\title{
Perceived availability and access limitations to ecosystem service well-being benefits increase in urban areas
}

\author{
Marie Lapointe $^{1}$, Georgina G. Gurney ${ }^{1}$ and Graeme S. Cumming ${ }^{1}$
}

\begin{abstract}
Access mechanisms can determine the benefits that people derive from a given ecosystem service supply. However, compared to ecosystem service availability, access has received little research attention. The relative importance of availability compared to access in limiting ecosystem service benefits is even less well understood. In cities, the observed disconnect between people and nature might result in part from changes in ecosystem service availability and access compared to rural areas. To address these research gaps, we compared perceived limitations to ecosystem service well-being benefits in urban and rural areas in the Solomon Islands. We predicted that more people would report being limited in ecosystem service benefits in urban than rural areas. Drawing on data from 200 respondents, we found that more urban dwellers reported being limited in both availability and access to the benefits that they derived from ecosystem services. Availability factors were the most frequently perceived limitations, although access played an important role for both provisioning and cultural services. In urban areas, poorer people, women, and older people identified the most limitations. Findings show the importance of investigating both ecosystem service availability and access to manage the environment in a way that sustains or increases benefits to people.
\end{abstract}

Key Words: coastal communities; disaggregation; rural areas; Solomon Islands; urbanization

\section{INTRODUCTION}

Access to ecosystem services is an essential, but often overlooked, step in the cascade in which ecosystems provide well-being benefits to humans through different ecological and social processes (Haines-Young and Potschin 2010, Daw et al. 2016). Sociallydifferentiated access to ecosystem services was identified as a research gap in the Millennium Ecosystem Assessment (MA 2005), a gap that still persists in recent regional Intergovernmental Science-Policy Platform for Biodiversity and Ecosystem Services (IPBES) reports (Mastrángelo et al. 2019). Failing to account for differential abilities to access ecosystem service benefits may result in unfair ecosystem service valuations and environmental management outcomes (Daw et al. 2011, Fisher et al. 2014, Gurney et al. 2015a). Issues of access might be especially relevant in cities where social inequalities, exclusion, and segregation are more pronounced and can even lead to conflict and violence (e.g., Smets and Salman 2008, Østby 2016). In addition, the availability of ecosystem services might also limit the benefits that people derive from ecosystems in built-up urban environments (Seto et al. 2013). Living in cities is thought to create a disconnect between people and nature (Louv 2009, Soga and Gaston 2016, Lapointe et al. 2019), even in recently urbanized societies (Lapointe et al. 2020). The reasons why urbanization alters the human-nature relationship are poorly understood, but might lie at the interface between the availability of and access to ecosystem service benefits. In this paper, we examined limitations to ecosystem service benefits in terms of availability and access as perceived by urban versus rural dwellers.

The role of access challenges the implicit assumption, in some ecosystem service research, that an increase in ecosystem service supply or availability will result in an increase in the benefits to people or what is called a trickle-down effect (Daw et al. 2011, Wieland et al. 2016). For example, the benefits derived from recreating in an urban park depend on the physical availability of parks near people, people's needs, values, and preferences. But benefits to people also depend on transportation and costs, regulations such as access hours, or feeling of insecurity; these are all examples of access mechanisms as described by Ribot and Peluso (2003:153) who defined access as "the ability to derive benefits from things," here ecosystem services.

People's perceptions of what limits their access to ecosystem service benefits can provide insights into how these benefits vary across societal groups. A socially differentiated approach to examining ecosystem service benefits is crucial for ensuring that environmental management is equitable (Gurney et al. 2015b). A few studies have examined the role of access mechanisms in mediating benefits derived from ecosystem services, drawing on a range of literature including environmental justice, livelihood capitals, environmental entitlements, and access theory (e.g. Hicks and Cinner 2014, Woodhouse et al. 2015, Berbés-Blázquez et al. 2017, Chaudhary et al. 2018, Kibria et al. 2018, Lau et al. 2020, Szaboova et al. 2020). Even if not framed in terms of access, socio-cultural valuation research on ecosystem services that disaggregates by socio-demographic characteristics (e.g., Lau et al. 2018) addresses access through what Ribot and Peluso (2003) call social identity; showing how beneficiaries' sociodemographic characteristics, e.g., gender and age, are associated to differential benefits. The studies cited above have expanded the understanding of ecosystem service access in three ways. First, they have demonstrated the importance of disaggregating ecosystem service analyses to understand who benefits, from what ecosystem service, and how. Second, they have shown the importance of looking at multiple dimensions of access, as described notably by Ribot and Peluso (2003). Third, access mechanisms appear to be in part context specific (Hicks and Cinner 2014).

Myers and Hansen's (2019) review of the literature drawing on the Theory of Access identified the lack of attention to how "materiality," i.e., physical characteristics of natural resources for 
example, influences derived benefits as an important research gap. In this paper, we contribute to meeting this gap by examining the physical characteristics affecting ecosystem service availability. In the ecosystem service literature, only a few authors investigating issues of access have also considered factors of availability. The physical characteristics examined in these studies include: land availability, coastal development, pollution, and geographic location (Brown et al. 2008), the quantity and quality of ecosystems (Milgroom et al. 2014), physical and spatial barriers (Wieland et al. 2016), land area (Kibria et al. 2018), distance (Szaboova et al. 2020), and weather (Lau et al. 2020). Investigating the physical characteristics affecting availability together with access mechanisms provides more complete and useful information for planning and management of ecosystem services.

The relative role of availability and access in mediating the benefits that people derive from ecosystem services is likely to differ between and within ecosystem service categories. Some ecosystem services may have, by nature or because of the context, excludable properties that make their access controllable by some and limited for others (Costanza 2008, Fisher et al. 2009). For example, provisioning (e.g., crops) can be commodified and some cultural (e.g., recreation) and regulating services (e.g., soil erosion prevention) may have excludable characteristics if the land upon which they are located is privatized. In contrast, several regulating services and some cultural services are public goods and have nonexcludable characteristics. For instance, the benefits obtained from climate regulation and air filtration provided by vegetation, or the educational or cultural values of nature, may be more limited by the availability of the necessary ecosystems rather than as a result of restricted access.

Urbanization can affect both availability and access to ecosystem services through alterations and destruction of ecosystems, increased population densities, and transformed socioeconomic contexts (Seto et al. 2013). As a result, urban dwellers may face limitations in the availability of certain ecosystem services such as natural areas to recreate, land for gardening and foraging, mitigation of air pollution, or shading and cooling from urban trees (Gómez-Baggethun et al. 2013). Furthermore, wealth appears as an important access mechanism, with wealthier people found to have better access to urban green (Sander and Zhao 2015, Tan and Samsudin 2017, Charnley et al. 2018) and blue areas (Unnikrishnan and Nagendra 2015). However, more research using social sciences approaches and involving stakeholders is needed in the urban ecosystem services literature (Haase et al. 2014, Luederitz et al. 2015). Moreover, most of the research on ecosystem services has taken place in wealthy modern cities, but conclusions might differ in societies of the Global South, notably because of differences in urban planning, but also in inhabitants' needs and values related to nature.

To address these research gaps, we compared urban to rural dwellers' perceptions of availability and access limitations to ecosystem service benefits in the Solomon Islands. Previous research has shown that, in the Solomon Islands, living in cities decreased perceived importance of and satisfaction toward ecosystem services (Lapointe et al. 2020). We explored potential underlying causes for these differences between urban and rural dwellers. The Solomon Islands is an interesting case study because of rapid urbanization (UN-Habitat 2012) and people's high dependency on nature (Solomon Islands National Statistics Office 2015). Our analysis was designed to test the hypothesis that urban dwellers were more likely to perceive and report limitations to ecosystem service benefits compared to rural dwellers because of differences in availability and access to ecosystem services due to urbanization.

\section{METHODS}

\section{Study sites and sampling design}

We compared two pairs of urban and rural sites (Fig. 1). We used a repeated paired design to minimize unwanted variation within a pair not caused by urbanization and the pairing was replicated to capture more of the variability associated with urbanization. One pair was located in the Guadalcanal province and included the capital, Honiara, and a village, Tamboko, $20 \mathrm{~km}$ away on the same coast. The second pair was located in the Western province consisting of the industrial town of Noro, and a village, Nusa Hope, located $30 \mathrm{~km}$ away as the crow flies. All sites had a diversity of ecosystems, with a range of anthropogenic influence. The ecosystems were terrestrial (forests, grasslands only found on Guadalcanal, gardens, people's backyard, plantations, beaches and coastlines), freshwater (rivers and streams, lakes, and wetlands), and marine (coral reefs, open ocean, mangroves, and seagrass beds, the latter found only at the Western province sites).

Fig. 1. Map of the study sites.

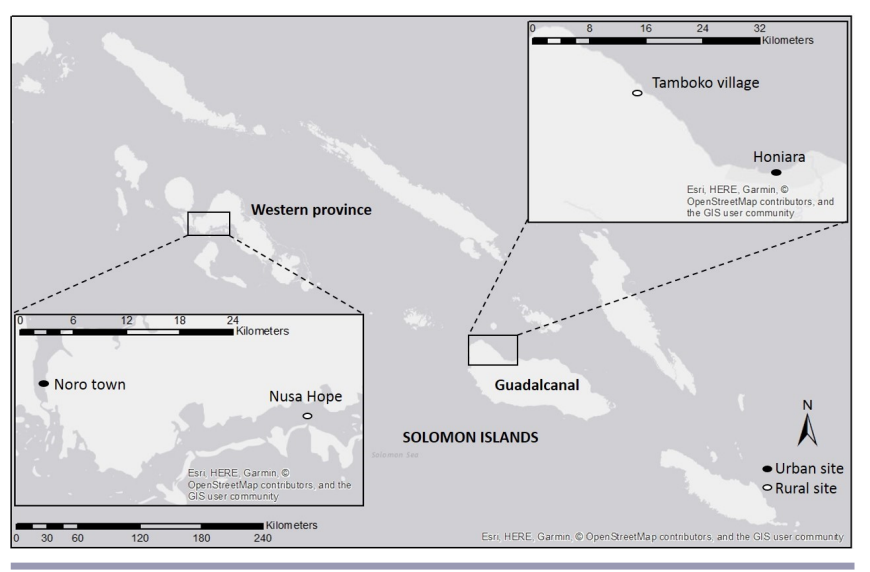

We conducted 200 semistructured interviews from September to December 2018, with 50 interviews per site. We sampled every second household in the research sites. Interviews were conducted in Pijin or in the local language by trained Solomon Islanders research assistants. Our sample is relatively well balanced with respect to a diversity of socio-demographic characteristics, including gender (Tables A.1 and A.2).

\section{Identification and classification of the limitations to ecosystem service availability and access}

Following expert interviews and focus group discussions, we selected the nine most important ecosystem services (Table A.3) among provisioning (food, materials, and firewood), regulating (provision of clean air, clean water, and soil protection), and cultural (recreation, culture, and stewardship) categories (for more details, see Lapointe et al. 2020). To identify ecosystem service availability and access limitations, we asked an open-ended 
Table 1. Availability and access limitations classification and correspondence with Ribot and Peluso's theory of access (2003).

\begin{tabular}{|c|c|c|c|}
\hline Limitation & Category & Example of answers & $\begin{array}{l}\text { Ribot and Peluso's (2003) } \\
\text { access mechanisms }\end{array}$ \\
\hline Quantity & Physical availability & There is not enough, there are too many people. & N/A \\
\hline Quality & Physical availability & It is degraded, polluted. & N/A \\
\hline Natural disasters & Physical availability & $\begin{array}{l}\text { Weather events, seasonality, natural disasters, pests and diseases, and } \\
\text { climate change. }\end{array}$ & N/A \\
\hline Location & Physical availability & It is too far. & N/A \\
\hline Context & Physical availability & Only found in rural areas. & N/A \\
\hline Right of access & $\begin{array}{l}\text { Rights/ } \\
\text { Management }\end{array}$ & Do not have the rights or ownership. & Right-based \\
\hline Management & Rights/ & Authorities restrict access, are corrupt, not doing their job. & Rights/ \\
\hline $\begin{array}{l}\text { (governance and law } \\
\text { enforcement) }\end{array}$ & Management & & Authority \\
\hline Social relations & $\begin{array}{l}\text { Social/ } \\
\text { Cultural }\end{array}$ & Social relations with wantok, conflicts with neighbors. & Social relations \\
\hline Security & $\begin{array}{l}\text { Social/ } \\
\text { Cultural }\end{array}$ & Criminality or dangerous animals. & Social relations \\
\hline Cultural & $\begin{array}{l}\text { Social/ } \\
\text { Cultural }\end{array}$ & Influence of other cultures, cultural diversity. & Social identity \\
\hline Knowledge & Human capital & Do not know where or how to access. & Knowledge \\
\hline Labor & Human capital & Lack of human resources, time, or interest. & Labor \\
\hline Economic & Material capital & Too expensive. & Capital \\
\hline Technology & Material capital & Lack of tools, equipment, infrastructure, transportation. & Technology \\
\hline
\end{tabular}

question in the household interviews about what limited the household from benefiting more from each ecosystem service. Respondents could give as many answers as they wanted. The answers were classified into the different access mechanisms and availability factors (Table 1). Our classification of limitations was derived from 50 pilot interviews and based on the theory of access (Ribot and Peluso 2003), as well as considering previous research on access to ecosystem services (Hicks and Cinner 2014, Milgroom et al. 2014, Wieland et al. 2016). Answers also included factors related to the availability of ecosystem services, which we added to our classification. There were also cases in which respondents did not feel limited in the benefits they received from ecosystem services and answers were recorded as such.

\section{Socio-demographic characteristics selection}

We used socio-demographic characteristics to disaggregate our findings: wealth, gender, age, education, and the time a person had been living in their community (Table A.1). We chose these characteristics because of their potential role in facilitating or limiting the access to ecosystem services. First, wealth can influence preferences and enable access to technologies and other type of capitals necessary to benefit from ecosystem services, sometimes resulting in a capture of the benefits by an elite (Fisher et al. 2014). Moreover, disparities in wealth are especially pronounced in urban areas (Behrens and Robert-Nicoud 2014). Second, men and women can have different needs, preferences for ecosystem services (Fisher et al. 2014, Fortnam et al. 2019), and gendered roles often differ in the coproduction of ecosystem services (e.g., Chaudhary et al. 2018, Lau et al. 2020). Third, age (e.g., Woodhouse et al. 2015, Lau et al. 2020), and fourth, education (e.g., Hicks and Cinner 2014, Kibria et al. 2018) can also influence the access to ecosystem service benefits, their specific relationship with ecosystem service benefits varying across studies. Fifth, in addition to these key characteristics, we assumed that time lived in the community would be a proxy for local knowledge as well as social inclusion, and could influence access to customary land in the Solomon Islands.

\section{Statistical analyses}

Urban-rural comparisons

We predicted that more urban dwellers would identify availability and access limitations to ecosystem services than rural dwellers. We tested our prediction across all 200 interview respondents who identified one or more of the 14 limitations for each of the nine ecosystem services. We used a generalized linear mixed model fitted with a binomial distribution using the "lme4" package (Bates et al. 2019) in R ( $\mathrm{R}$ Core Team 2019). The response variable was the presence or absence of a limitation. Urbanization level (urban versus rural), ecosystem services (nine levels), limitations ( 14 levels), and the interaction between these three variables were the fixed effects. Limitations that were reported by $5 \%$ or less people per ecosystem service were removed from the analyses. In all cases, we added respondents as a random factor to control for the nonindependence of multiple responses per respondent. We did not include the study site in the random structure because it has only four levels; we would have included it as a fixed effect, but it was not possible in this case because each site was nested within an urbanization level. We tested whether the fixed effects contributed significantly to the models with an analysis of deviance (Wald test) using the "Anova" function of the "car" package (Fox et al. 2019). We performed post-hoc multiple comparisons with the "emmeans" package (Lenth et al. 2019) with a Tukey correction for multiple testing. Assumptions were tested with the "Dharma" package (Hartig 2019).

Disaggregation of limitations within urban and rural areas

Within urban and rural areas (100 respondents for each), we tested the effect of the five socio-demographic characteristics. We again used generalized linear mixed models fitted with a binomial distribution. The response variable was the same as above. The 
Fig. 2. Frequency of urban and rural dwellers identifying a limitation for each ecosystem service. The total number of mentions of a limitation, and of limitations per ecosystem service are indicated in parentheses for urban and rural, respectively.

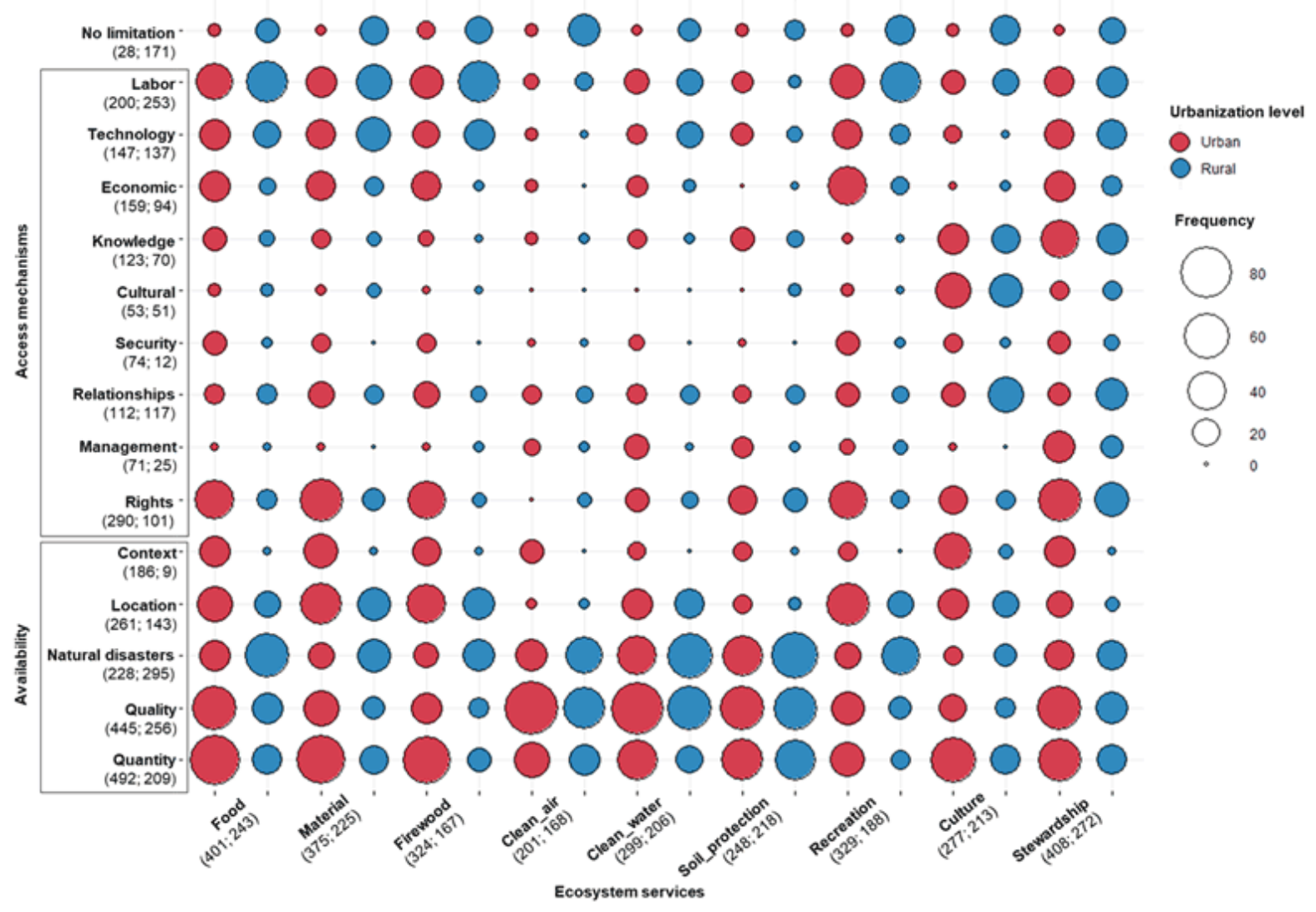

fixed effects were: ecosystem services or limitations, and the five socio-demographic characteristics. We performed the analysis per ecosystem service and also per limitation. We did not include interaction terms because of the large number of variables in the models. In addition to the assumptions tested above, we also checked, with variation inflation factors, that socio-demographic characteristics were not collinear.

\section{RESULTS}

Comparison of perceived ecosystem service availability and access limitations between urban and rural areas

Most limitations to ecosystem service benefits were reported for stewardship, food, and materials in both urban and rural areas (Fig. 2). However, the number of people mentioning limitations were fewer in rural than in urban areas. The average number of limitations reported by rural dwellers was also lower compared to urban dwellers (Table 2). Additionally, the most often perceived limitations differed between urban and rural areas. The quantity of ecosystem services was the most often cited limitation in urban areas, but it came third in importance in rural areas. The context limitation indicated that an ecosystem service could not be found in an urban context, and was an important limitation for several ecosystem services in urban areas. Security was not one of the most frequent limitations identified; it was mostly mentioned in urban areas for provisioning and cultural services. In addition, there were more people who reported not being limited by anything in rural than in urban areas.

Table 2. Mean number of limitations and standard deviation per ecosystem service per person in urban and rural areas.

\begin{tabular}{lllllll}
\hline \hline Category & \multirow{2}{*}{ Ecosystem service } & \multicolumn{2}{c}{ Urban } & & \multicolumn{2}{c}{ Rural } \\
\cline { 3 - 4 } \cline { 6 - 7 } & & Mean & SD & & Mean & SD \\
\hline Provisioning & Food & 3.98 & 2.42 & & 2.29 & 1.68 \\
& Materials & 3.73 & 2.34 & & 2.04 & 1.51 \\
& Firewood & 3.17 & 2.19 & & 1.72 & 1.32 \\
Regulating & Clean air & 1.98 & 1.15 & & 1.39 & 1.23 \\
& Clean water & 3.00 & 1.93 & & 2.12 & 1.33 \\
& Soil protection & 2.47 & 1.39 & & 2.08 & 1.21 \\
Cultural & Recreation & 3.26 & 1.80 & & 1.64 & 1.36 \\
& Culture & 2.81 & 1.65 & & 1.90 & 1.48 \\
& Stewardship & 4.10 & 2.89 & & 2.54 & 1.80 \\
\hline
\end{tabular}

The model comparing urban and rural areas (Fig. 3) showed that several limitations related to ecosystem service availability and access were significantly higher in urban areas. Rural dwellers only identified significantly more limitations related to natural disasters for provisioning services, soil protection, and recreation; 
social relationships for culture and stewardship; and labor in the case of firewood. Consequently, we rejected the null hypothesis of no difference between the limitations perceived between urban and rural dwellers.

Fig. 3. Comparison of limitations reported per ecosystem service between urban and rural dwellers for (a) provisioning, (b) regulating, and (c) cultural services. Values represent estimated marginal means with associated confidence limits from multiple comparisons following a logistic regression.
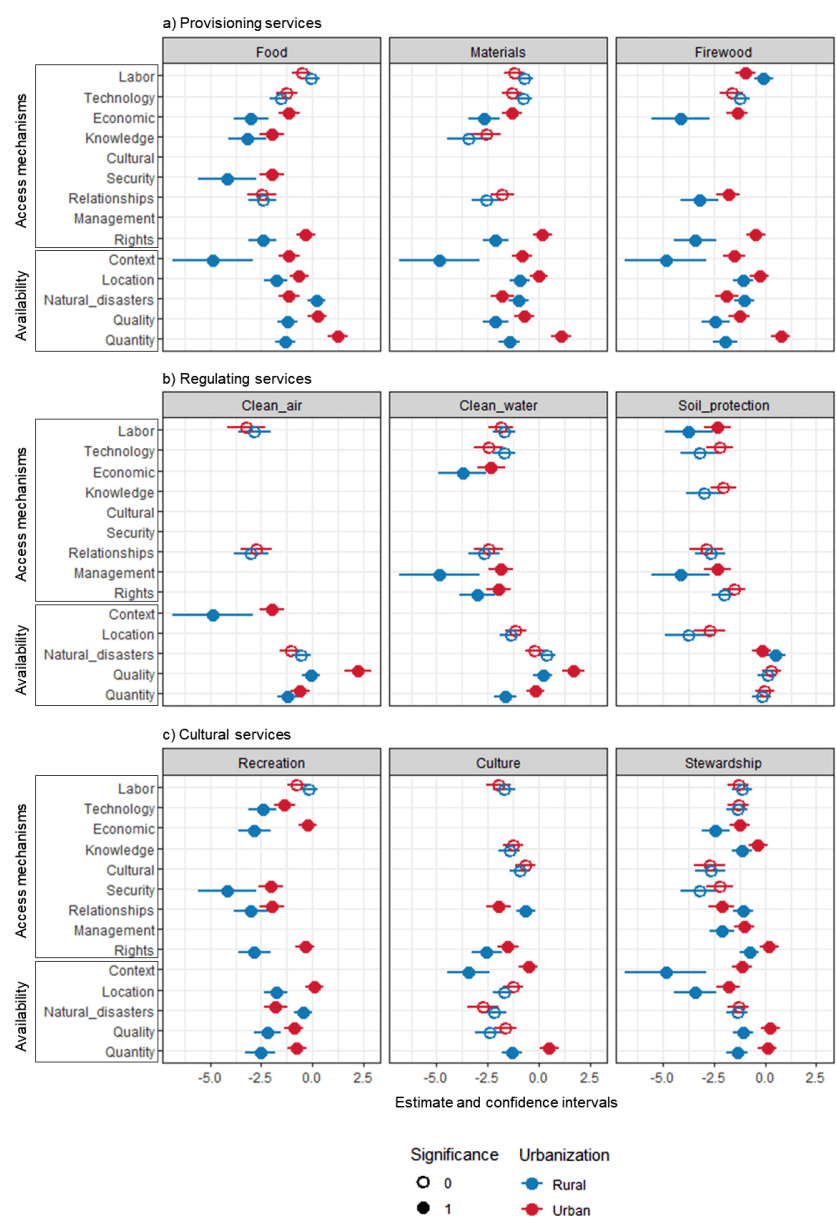

Provisioning services (food, materials, and firewood) were found to be limited by questions of availability in urban areas, mainly in terms of quantity: $75 \%$ of urban dwellers reported that the quantity of food was limiting, $72 \%$ for materials, and $66 \%$ for firewood. In terms of access mechanisms, access rights were the most limiting factor in urban areas being reported by $43 \%$ of urban dwellers in the case of food, $54 \%$ for materials, and $40 \%$ for firewood; whereas issues of rights were reported significantly less frequently in rural areas $(10 \%, 13 \%$, and $4 \%$ for food, materials, and firewood, respectively). Furthermore, urban dwellers were also more frequently restricted in their access to food compared to rural dwellers by economic, knowledge, and security issues. The costs also limited access to materials in urban compared to rural areas. Economic and social relationships mechanisms limited further the access to firewood for urban dwellers. In contrast, the most frequently cited limitations to provisioning service benefits in rural areas were related to labor (e.g., motivation, time), technology, and natural disasters (e.g., cyclones, pests).

Regulating services were limited mainly by availability issues, both in urban and rural contexts, although significantly more so in urban areas. The quality of regulating services was the main issue in urban areas. For example, air and water quality was reported as limiting by $88 \%$ and $81 \%$ of urban dwellers respectively, compared to $49 \%$ and $55 \%$ by rural dwellers. The difference in availability factors for soil protection did not differ between urban and rural areas, except for natural disasters that had a significantly higher probability of being identified in rural areas. Regulating services were the least impacted ecosystem service category by access mechanisms, although issues of rights were also significantly more frequent in urban than in rural areas for both clean water and soil protection. There were also more economic limitations to access to clean water in urban compared to rural areas.

Cultural services, being quite different from one another, presented varying patterns of limiting factors, although more people perceived limitations for all three services in urban than in rural areas. In urban areas, people were limited in their opportunities to recreate in nature by the location $(52 \%)$, the costs $(45 \%)$, and the rights to access $(42 \%)$ mainly beaches. In rural areas, the main limitations were related to damages caused by natural disasters $(41 \%)$ or the will and time to recreate $(47 \%$, included in labor). Culture in urban areas was mentioned as being less present ( $61 \%$ of urban dwellers identifying quantity, and $39 \%$ context), and was associated to the mix of different cultures (36\%), and an erosion of traditional knowledge $(25 \%)$. In rural areas, the different cultures $(22 \%)$ and the loss of traditional knowledge $(31 \%)$ were also reported to limit access to culture, but also relationships with people from different cultures $(37 \%)$. Stewardship was limited by both availability and access mechanisms in both urban and rural areas. In urban areas, limitations related to the quantity ( $52 \%$ of respondents) and quality $(55 \%)$ of natural areas were significantly higher than in rural areas. Rights also played an important role for both urban $(54 \%)$ and rural $(34 \%)$ dwellers, and were in fact the main limitation in rural areas. Furthermore, urban dwellers were significantly more limited by knowledge $(42 \%)$, management $(29 \%)$, and economic $(25 \%)$ mechanisms in their stewardship of natural areas, whereas rural dwellers were more so by social relationships $(28 \%)$.

\section{Disaggregation by socio-demographic characteristics within urban and rural areas}

We found significant effects of all five socio-demographic characteristics on some ecosystem service types in urban areas, and of the proportion of time living in the community, education level, and age in rural areas (Fig. 4). As wealth increased in urban areas, perceived limitations decreased and significantly so for food, firewood, and stewardship. A greater proportion of life spent in a given urban or rural community tended to decrease the number of perceived limitations, although this was only significant for clean air and culture in urban areas, and soil protection in rural areas. In general, women tended to perceive more limitations compared to men, significantly so for firewood, 
Fig. 4. Relationship between socio-demographic characteristics and number of perceived limitations per ecosystem service types in urban and rural areas. Limitations were included in the models, but are omitted from the graph. Urban and rural analyses were performed separately for each ecosystem service, but are illustrated in the same plots. MSL, material style of life.

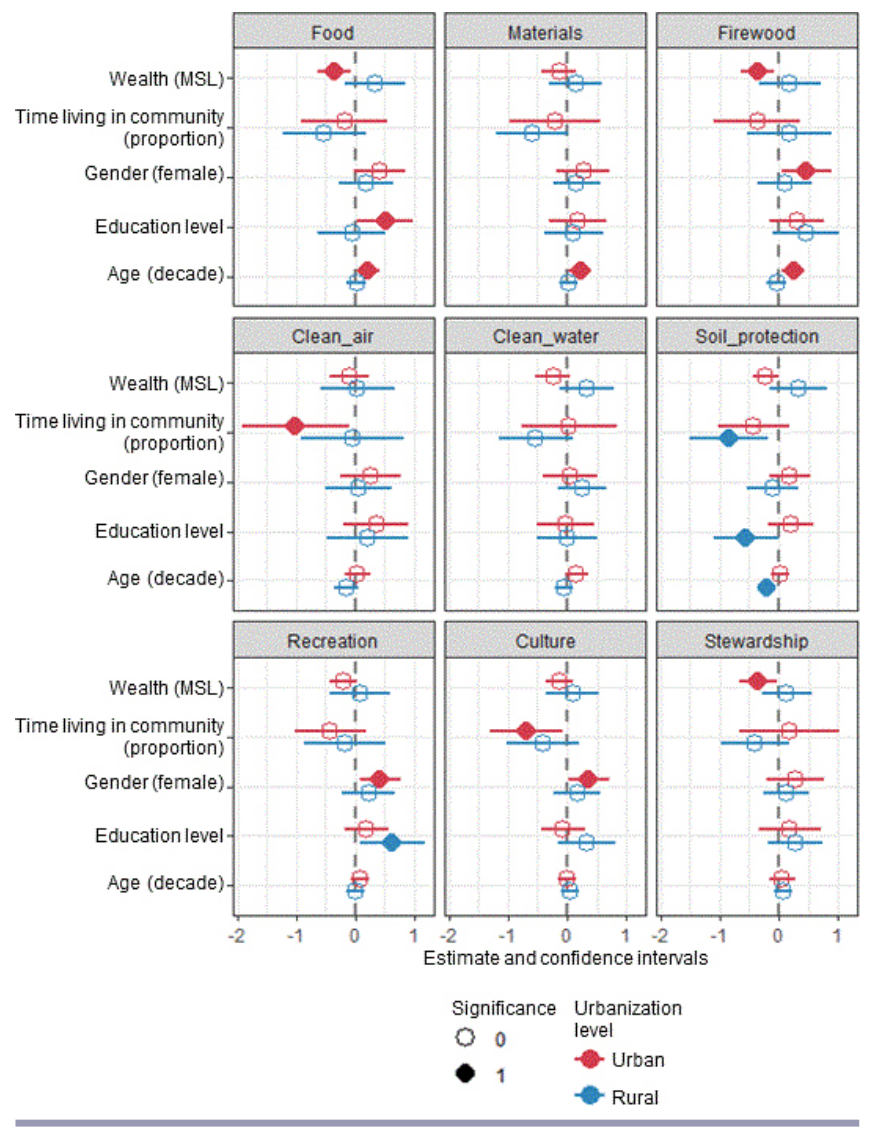

recreation, and culture in urban areas. The patterns for the effect of formal education varied: education level increased perceived limitations for food in urban area and for recreation in rural areas, but decreased perceived limitations to soil protection in rural areas. Older people in urban areas perceived more limitations to all provisioning services. The trend was different in rural areas, with older people identifying significantly fewer limitations for soil protection.

We also found a few significant relationships between sociodemographic characteristics and the type of limitation within urban and rural areas (Fig. 5). In urban areas, increased wealth decreased the probability of identifying natural disasters, technology, and labor as limitations to ecosystem service benefits. The pattern was opposite in rural areas with greater wealth associated with a higher probability to report quantity limitations. The longer people had been living in their urban or rural community, the fewer limitations to ecosystem service quantity were perceived. Women in urban areas perceived fewer management limitations, but more security and labor limitations compared to men. The only clear effect of formal education was to increase the likelihood of perceiving knowledge limitations in
Fig. 5. Relationship between socio-demographic characteristics and the number of perceived limitations to ecosystems services relating to (a) availability and (b) access in urban and rural areas. Ecosystem service types were controlled for in the model, but are omitted from the graph. Urban and rural analyses were performed separately for each limitation, but are illustrated in the same plots.
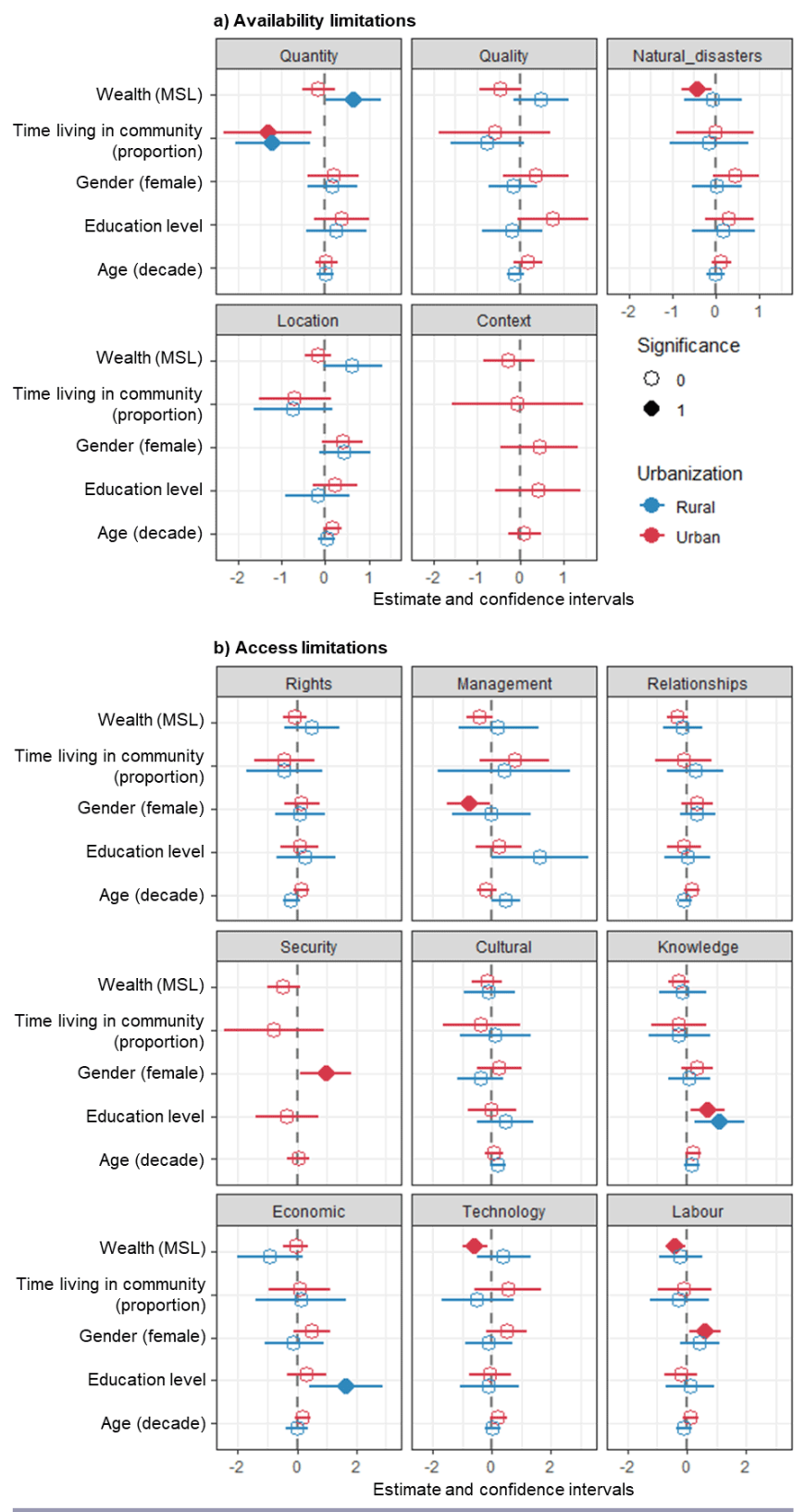

both urban and rural areas. Age was not significantly related to either availability or access limitations.

\section{DISCUSSION}

We found strong support for our hypothesis that significantly more urban than rural dwellers would report limitations to ecosystem service benefits in the Solomon Islands. Urban dwellers 
also identified, on average, more limitations per ecosystem service than rural dwellers. Most limitations identified by urban dwellers were related to ecosystem service availability. The access mechanisms identified, especially issues of rights, also played an important role for provisioning and cultural services. When we disaggregated our findings according to socio-demographic characteristics, we found that wealth, gender, and age had a significant relationship with perceived limitations in urban areas.

Our findings indicate that, to a great extent, landscape and seascape physical transformations resulting from urbanization, e.g., urban development, overexploitation, and pollution, reduce perceived ecosystem service availability, the most often reported limitations to ecosystem service benefits. The quantity of provisioning services available (food, materials, and firewood) was a more important limitation for urban dwellers than quality and location. Ecosystem service quality, including pollution of water, air, and soil degradation, was the main limitation for regulating services in urban areas. For cultural services in urban areas, recreation was limited mainly by distance, traditional culture was often perceived as absent from urban contexts, and stewardship, i.e., the will to protect local ecosystems, was restricted by both the quantity and quality of natural areas to conserve. Our findings demonstrate the importance of considering what Myers and Hansen (2019) named the materiality of the "thing" when addressing questions of access to ecosystem services.

Several access mechanisms were more frequently identified in urban than in rural areas, although they were relatively less frequently cited than availability issues, especially for provisioning and regulating services. For all provisioning services, rights of use were the main limiting access mechanism, and were significantly more frequent in urban compared to rural areas because, as material goods, provisioning services have excludable properties that allow their commodification (Costanza 2008, Fisher et al. 2009). In contrast, because of their mostly nonexcludable, public good nature (Costanza 2008), regulating services were the least impacted category of ecosystem services through access mechanisms. However, issues of rights were also significantly more frequent in urban than in rural areas for both clean water and soil protection because the ecosystems providing these services can be located on private land. The cultural services that we assessed were all very different in nature from one another and consequently presented different patterns of access limitations with the exception of rights, which were more often perceived as limiting in urban than in rural areas for all cultural services. The relative importance of rights of use compared to other access mechanisms probably stems in part from the customary tenure of land in the Solomon Islands. About $83 \%$ of the land is under customary tenure in the Solomon Islands and access to noncustomary owners is restricted (Corrin 2012). For example, most of the land around Honiara is under customary tenure, which limits the geographical expansion of the city (Foukona 2017).

Only a few other studies have addressed both ecosystem service access and availability, but were conducted only in rural areas (e.g., Milgroom et al. 2014, Wieland et al. 2016). Like ours, these studies showed that, although looking at availability or access limitations separately is informative, it provides an incomplete picture of the potential benefits that certain people can derive from ecosystems. In fact, availability and access limitations can interact (Milgroom et al. 2014) resulting in compounded impacts (Wieland et al. 2016). Therefore, understanding the role of ecosystem service availability and access limitations is essential to inform environmental management that aims to improve the flow of benefits to people.

Disaggregation highlighted a few trends between perceived availability and access limitations and the socio-demographic characteristics examined (including wealth, gender, age, time living in a community, and formal education). Fewer wealthier urban dwellers identified limitations to provisioning (food and firewood) and cultural services (stewardship), and were less likely to report being limited by natural disasters, technology, and labor. The reasons for this finding are likely to be twofold. First, the need for some ecosystem services might be lower for wealthier people who can afford alternatives to food, materials, firewood, and recreation opportunities for example. Second, wealth can increase access to other types of capitals necessary in the coproduction of most ecosystem services (sensu Palomo et al. 2016), notably natural capital through land ownership, but also technology (manufactured capital) and labor (human capital) as shown here. Increases in the availability of and access to ecosystem services for wealthy people, often at the expense of poorer people, is often referred to as elite capture (e.g., Fisher et al. 2014). These two hypotheses are not mutually exclusive, and it is more likely that a combination of both is at play. Interestingly, wealth had an opposite effect in rural areas where wealthier people reported more limitations in terms of the quantity of ecosystem services available. An explanation might be that, in rural areas, wealth is derived from selling provisioning services. Therefore, people who take part in the cash economy might be more prone to seeing limitations of revenue generation from provisioning services than people who use ecosystem services mainly for subsistence.

In contrast to the effect of wealth, women and older people in urban areas perceived more limitations. Women reported more limitations to provisioning and cultural service benefits, as well as more security and labor limitations. Women might be limited in their access to cultural services in part because of a heavier work load associated with reduction in leisure time, in addition to restricted access to some tambu areas (Asian Development Bank 2015). Women are also more responsible for gathering some provisioning services for the household (food, firewood, and medicines) and thus might be more aware of limitations. All these factors might have a greater impact in urban areas where ecosystem service availability is lower. In contrast, men in urban areas reported more management limitations; this may be because men are traditionally in charge of decision making in the Solomon Islands (Asian Development Bank 2015), but taking part in decision making might be harder outside of customarily owned land, as is urban areas. Older people also perceived more limitations to provisioning service benefits in urban areas. It is possible that older people might have higher expectations for ecosystem service benefits, having witnessed less transformed environments during their lifetime.

There were common trends shared among urban and rural dwellers regarding the effect of time living in a community and formal education. The longer someone had been in a community, 
the less they were limited by the quantity of ecosystem services available to them in both urban and rural areas. Although the exact mechanisms need to be teased apart, this trend could be related to negotiating access with customary owners and developing local knowledge. When formal education level had a significant effect, it mostly increased perceived limitations for food in urban areas and recreation in rural areas. It also increased perceived limitations in traditional knowledge in both urban and rural areas, and economic limitations in rural areas. Thus, formal education might raise awareness of ecosystem service availability and access limitations. However, the fact that the direction of the effect is the same in both urban and rural areas could indicate that formal education may conflict with traditional knowledge. This is likely because achieving higher education levels in the Solomon Islands requires attending school or university in urban areas; and the livelihoods typically adopted by people with high levels of formal education may be less connected to nature.

Most of these socio-demographic characteristics, i.e., gender, age, education, and time living in the community, can be considered as social identity access mechanisms according to Ribot and Peluso (2003). To our knowledge, our study is the first to combine the examination of social identity access mechanisms, using sociodemographic data, with perceived availability and access limitations to ecosystem service benefits in urban areas. Doing so is important for urban planning and environmental management, especially in countries of the Global South, like the Solomon Islands, where avoiding unfair trade-offs in ecosystem service benefits between people is critical given the precarious situations that people already live in.

With this paper, we wanted to understand the reasons why fewer urban dwellers benefit from ecosystem services in the Solomon Islands, and which factors are responsible for the altered humannature relationship. Previous research has shown that urban dwellers were less satisfied than rural dwellers with the benefits that they derive from ecosystem services (Lapointe et al. 2020). In other words, urban dwellers' expectations toward ecosystem services were not met and they would have liked to benefit more from ecosystems. Taken together these findings suggest that in the Solomon Islands, urban dwellers are not voluntarily disconnected from nature, but rather become disconnected because of the reduction in ecosystem service availability and access, mainly through rights of use, in urban environments. Therefore, in urban areas, increasing the supply of ecosystem services would increase benefits to people, as long as legal access mechanisms were not compromised for provisioning and cultural services, especially for poorer people and women.

\section{Caveat and future directions}

A potential limitation of our research is that the villages that we selected were rather populous by Solomon Islands standards; larger population sizes were needed to balance our sampling design. The high population densities in Tamboko and Nusa Hope villages might have limited the availability and access to ecosystem service benefits to some people, as the proportion of time spent in the community seems to point out. Thus, the contrast between urban and rural areas might even have been larger if we had chosen smaller villages.

Finally, we identified two important future research directions that could be useful in urban planning and environmental management. First, interdisciplinary research is needed on feedback mechanisms that operate between ecosystem service availability and access mechanisms, and the benefits and impacts on people's well-being. Second, research on availability of and access to ecosystem services should be spatially explicit, in particular to alleviate or avoid aggravating social inequalities. This can be achieved through participatory mapping interviews or focus groups with ecosystem service beneficiaries (e.g., Brown et al. 2012), and is expected to be particularly useful for informing urban planning, including in relation to environmental features.

To summarize, we found the availability of provisioning, regulating, and cultural services, as well as access to provisioning and cultural services to be partly responsible for the disconnect between nature and people observed in urban areas. In fact, we found that urban dwellers identified significantly more availability and access limitations to the well-being benefits that they derived from ecosystem services compared to rural dwellers in the Solomon Islands. In addition to these general trends in urban areas, poorer, older people, and women reported more limitations to ecosystem service benefits. These results show the importance of investigating both the availability of and access to ecosystem services if environmental management and urban planning are to address the limitations faced by different social groups, and thus promote socially just access to nature's benefits.

Responses to this article can be read online at: https://www.ecologyandsociety.org/issues/responses. $\mathrm{php} / 12012$

\section{Acknowledgments:}

This research was funded by a James S. McDonnell complexity scholar award to GSC and the ARC Centre of Excellence for Coral Reef Studies. We are grateful to the Ministry of Education of the Solomon Islands, Honiara City Council, Noro Town Council (in particular, David Mamupio), and the Tamboko and Nusa Hope village leaders who gave the authorizations to conduct the research; all the interviews and focus group discussions participants; Mary Tahu and Alec Hughes who helped to find research assistants; and research assistants, especially Jacinta Anasimae, Virginia Leve, and Bridget Tova. Finally, we thank two anonymous reviewers for their kind and constructive comments on our manuscript.

\section{Data Availability:}

The data is available on the JCU online data repository, https://doi. org/10.25903/3s4e-t744.

\section{LITERATURE CITED}

Asian Development Bank. 2015. Solomon Islands country gender assessment. Asian Development Bank, Mandaluyong City, Philippines.

Bates, D., M. Maechler, B. Bolker, S. Walker, R. H. B. Christensen, H. Singmann, B. Dai, F. Scheipl, G. Grothendieck, P. Green, and J. Fox. 2019. lme4: Linear mixed-effects models using Eigen and S4. 
Behrens, K., and F. Robert-Nicoud. 2014. Do cities widen the gap between rich and poor? World Economic Forum, Cologny, Switzerland. [online] URL: https://www.weforum.org/agenda/2014/07/ cities-urbanization-rich-poor-inequality/

Berbés-Blázquez, M., M. J. Bunch, P. R. Mulvihill, G. D. Peterson, and B. van Wendel de Joode. 2017. Understanding how access shapes the transformation of ecosystem services to human wellbeing with an example from Costa Rica. Ecosystem Services 28:320-327. https://doi.org/10.1016/j.ecoser.2017.09.010

Brown, G., J. M. Montag, and K. Lyon. 2012. Public participation GIS: a method for identifying ecosystem services. Society \& Natural Resources 25(7):633-651. https://doi.org/10.1080/08941$\underline{920.2011 .621511}$

Brown, K., T. Daw, S. Rosendo, M. Bunce, and N. Cherrett. 2008. Ecosystem services for poverty alleviation: marine \& coastal situational analysis, synthesis report. Natural Environment Research Council /Department for International Development, London, UK.

Charnley, S., R. J. McLain, and M. R. Poe. 2018. Natural resource access rights and wrongs: nontimber forest products gathering in urban environments. Society \& Natural Resources 31(6):734-750. https://doi.org/10.1080/08941920.2017.1413696

Chaudhary, S., A. McGregor, D. Houston, and N. Chettri. 2018. Environmental justice and ecosystem services: a disaggregated analysis of community access to forest benefits in Nepal. Ecosystem Services 29:99-115. https://doi.org/10.1016/j.ecoser.2017.10.020

Corrin, J. C. 2012. Customary land in Solomon Islands: a victim of legal pluralism. Pages 221-249 in A. Angelo, O. Aimot, and Y.L. Sage, editors. Droit foncier et gouvernance judiciaire dans Le Pacifique: Land law and governance in the South Pacific. Research Paper No. 12-11. University of Queensland TC Beirne School of Law, St Lucia, Queensland, Australia. [online] URL: https:// papers.ssrn.com/sol3/papers.cfm?abstract $\mathrm{id}=2353666$

Costanza, R. 2008. Ecosystem services: multiple classification systems are needed. Biological Conservation 141(2):350-352. https://doi.org/10.1016/j.biocon.2007.12.020

Daw, T., K. Brown, S. Rosendo, and R. Pomeroy. 2011. Applying the ecosystem services concept to poverty alleviation: the need to disaggregate human well-being. Environmental Conservation 38 (04):370-379. https://doi.org/10.1017/S0376892911000506

Daw, T. M., C. Hicks, K. Brown, T. Chaigneau, F. JanuchowskiHartley, W. Cheung, S. Rosendo, B. Crona, S. Coulthard, C. Sandbrook, C. Perry, S. Bandeira, N. A. Muthiga, B. SchulteHerbrüggen, J. Bosire, and T. R. McClanahan. 2016. Elasticity in ecosystem services: exploring the variable relationship between ecosystems and human well-being. Ecology and Society 21(2):11. https://doi.org/10.5751/ES-08173-210211

Fisher, B., R. K. Turner, and P. Morling. 2009. Defining and classifying ecosystem services for decision making. Ecological Economics 68(3):643-653. https://doi.org/10.1016/j.ecolecon.2008.09.014

Fisher, J. A., G. Patenaude, K. Giri, K. Lewis, P. Meir, P. Pinho, M. D. Rounsevell, and M. Williams. 2014. Understanding the relationships between ecosystem services and poverty alleviation: a conceptual framework. Ecosystem Services 7:34-45. https://doi. org/10.1016/j.ecoser.2013.08.002

Fortnam, M., K. Brown, T. Chaigneau, B. Crona, T. M. Daw, D. Gonçalves, C. Hicks, M. Revmatas, C. Sandbrook, and B. SchulteHerbruggen. 2019. The gendered nature of ecosystem services. Ecological Economics 159:312-325. https://doi.org/10.1016/j. ecolecon.2018.12.018

Foukona, J. D. 2017. Solomon Islands' urban land tenure: growing complexity. State, Society \& Governance in Melanesia Program, Australian National University, Canberra, Australia. [online] URL: https://openresearch-repository.anu.edu.au/ bitstream/1885/141295/1/IB2017.5\%20Joe\%20Foukona.pdf

Fox, J., S. Weisberg, B. Price, D. Adler, D. Bates, G. Baud-Bovy, B. Bolker, S. Ellison, D. Firth, M. Friendly, G. Gorjanc, S. Graves, R. Heiberger, R. Laboissiere, M. Maechler, G. Monette, D. Murdoch, H. Nilsson, D. Ogle, B. Ripley, W. Venables, S. Walker, D. Winsemius, A. Zeileis, and R-Core. 2019. Companion to applied regression. [online] URL: https://r-forge.r-project.org/projects/ $\underline{\text { carl }}$

Gómez-Baggethun, E., Å. Gren, D. N. Barton, J. Langemeyer, T. McPhearson, P. O'Farrell, E. Andersson, Z. Hamstead, and P. Kremer. 2013. Urban ecosystem services. Pages 175-251 in $\mathrm{T}$. Elmqvist, M. Fragkias, J. Goodness, B. Güneralp, P. J. Marcotullio, R. I. McDonald, S. Parnell, M. Schewenius, M. Sendstad, K. C. Seto, and C. Wilkinson, editors. Urbanization, biodiversity and ecosystem services: challenges and opportunities: a global assessment. Springer, Dordrecht, The Netherlands. https://doi.org/10.1007/978-94-007-7088-1_11

Gurney, G. G., R. L. Pressey, N. C. Ban, J. G. Álvarez-Romero, S. Jupiter, and V. M. Adams. 2015b. Efficient and equitable design of marine protected areas in Fiji through inclusion of stakeholder-specific objectives in conservation planning. Conservation Biology 29(5):1378-1389. https://doi.org/10.1111/ cobi. 12514

Gurney, G. G., R. L. Pressey, J. E. Cinner, R. Pollnac, and S. J. Campbell. 2015a. Integrated conservation and development: evaluating a community-based marine protected area project for equality of socioeconomic impacts. Philosophical Transactions of the Royal Society B 370(1681):20140277. https://doi.org/10.1098/ rstb.2014.0277

Haase, D., N. Larondelle, E. Andersson, M. Artmann, S. Borgström, J. Breuste, E. Gomez-Baggethun, Å. Gren, Z. Hamstead, R. Hansen, et al. 2014. A quantitative review of urban ecosystem service assessments: concepts, models, and implementation. Ambio 43(4):413-433. https://doi.org/10.1007/ s13280-014-0504-0

Haines-Young, R., and M. Potschin. 2010. The links between biodiversity, ecosystem services and human well-being. Pages 110-139 in D. G. Raffaelli and C. L. J. Frid, editors. Ecosystem ecology: anew synthesis. Cambridge University Press, Cambridge, UK. https://doi.org/10.1017/CBO9780511750458.007

Hartig, F. 2019. DHARMa: residual diagnostics for hierarchical (multi-level / mixed) regression models. $\mathrm{R}$ package version 0.2.4. [online] URL: http://florianhartig.github.io/DHARMa/ 
Hicks, C. C., and J. E. Cinner. 2014. Social, institutional, and knowledge mechanisms mediate diverse ecosystem service benefits from coral reefs. Proceedings of the National Academy of Sciences 111(50):17791-17796. https://doi.org/10.1073/pnas.1413473111

Kibria, A. S., R. Costanza, C. Groves, and A. M. Behie. 2018. The interactions between livelihood capitals and access of local communities to the forest provisioning services of the Sundarbans Mangrove Forest, Bangladesh. Ecosystem Services 32:41-49. https://doi.org/10.1016/j.ecoser.2018.05.003

Lapointe, M., G. S. Cumming, and G. G. Gurney. 2019. Comparing ecosystem service preferences between urban and rural dwellers. BioScience 69(2):108-116. https://doi.org/10.1093/ biosci/biy 151

Lapointe, M., G. G. Gurney, and G. S. Cumming. 2020. Urbanization alters ecosystem service preferences in a small island developing state. Ecosystem Services 43:101109. https:// doi.org/10.1016/j.ecoser.2020.101109

Lau, J. D., J. E. Cinner, M. Fabinyi, G. G. Gurney, and C. C. Hicks. 2020. Access to marine ecosystem services: examining entanglement and legitimacy in customary institutions. World Development 126:104730. https://doi.org/10.1016/j.worlddev.2019.104730

Lau, J. D., C. C. Hicks, G. G. Gurney, and J. E. Cinner. 2018. Disaggregating ecosystem service values and priorities by wealth, age, and education. Ecosystem Services 29:91-98. https://doi. org/10.1016/j.ecoser.2017.12.005

Lenth, R., H. Singmann, J. Love, P. Buerkner, and M. Herve. 2019. Estimated marginal means, aka least-squares means. R package version 1.3.3. [online] URL: https://github.com/rvlenth/ emmeans

Louv, R. 2009. Do our kids have nature-deficit disorder? Educational Leadership 67(4):24-30.

Luederitz, C., E. Brink, F. Gralla, V. Hermelingmeier, M. Meyer, L. Niven, L. Panzer, S. Partelow, A.-L. Rau, R. Sasaki, et al. 2015. A review of urban ecosystem services: six key challenges for future research. Ecosystem Services 14:98-112. https://doi.org/10.1016/ j.ecoser.2015.05.001

Mastrángelo, M. E., N. Pérez-Harguindeguy, L. Enrico, E. Bennett, S. Lavorel, G. S. Cumming, D. Abeygunawardane, L. D. Amarilla, B. Burkhard, B. N. Egoh, et al. 2019. Key knowledge gaps to achieve global sustainability goals. Nature Sustainability 2:1115-1121. https://doi.org/10.1038/s41893-019-0412-1

Milgroom, J., K. E. Giller, and C. Leeuwis. 2014. Three interwoven dimensions of natural resource use: quantity, quality and access in the Great Limpopo Transfrontier Conservation Area. Human Ecology 42(2):199-215. https://doi.org/10.1007/ s10745-013-9635-3

Millennium Ecosystem Assessment (MA). 2005. Ecosystems and human well-being. MA, Island Press, Washington, D.C., USA.

Myers, R., and C. P. Hansen. 2020. Revisiting a theory of access: a review. Society \& Natural Resources 33(2):146-166. https://doi. org/10.1080/08941920.2018.1560522
Østby, G. 2016. Rural-urban migration, inequality and urban social disorder: evidence from African and Asian cities. Conflict Management and Peace Science 33(5):491-515. https://doi. org/10.1177/0738894215581315

Palomo, I., M. R. Felipe-Lucia, E. M. Bennett, B. Martín-López, and U. Pascual. 2016. Chapter six-disentangling the pathways and effects of ecosystem service co-production. Advances in Ecological Research 54:245-283. https://doi.org/10.1016/bs.aecr.2015.09.003

R Core Team. 2019. R: A language and environment for statistical computing. R Foundation for Statistical Computing, Vienna, Austria.

Ribot, J. C., and N. L. Peluso. 2003. A theory of access. Rural Sociology 68(2):153-181. https://doi.org/10.1111/j.1549-0831.2003. tb00133.x

Sander, H. A., and C. Zhao. 2015. Urban green and blue: Who values what and where? Land Use Policy 42:194-209. https://doi. org/10.1016/j.landusepol.2014.07.021

Seto, K. C., S. Parnell, and T. Elmqvist. 2013. A global outlook on urbanization. Pages 1-12 in T. Elmqvist, M. Fragkias, J. Goodness, B. Güneralp, P. J. Marcotullio, R. I. McDonald, S. Parnell, M. Schewenius, M. Sendstad, K. C. Seto, and C. Wilkinson, editors. Urbanization, biodiversity and ecosystem services: challenges and opportunities: a global assessment. Springer, Dordrecht, The Netherlands. https://doi. org/10.1007/978-94-007-7088-1_1

Smets, P., and T. Salman. 2008. Countering urban segregation: theoretical and policy innovations from around the globe. Urban Studies 45(7):1307-1332. https://doi.org/10.1177/0042098008090676

Soga, M., and K. J. Gaston. 2016. Extinction of experience: the loss of human-nature interactions. Frontiers in Ecology and the Environment 14(2):94-101. https://doi.org/10.1002/fee.1225

Solomon Islands National Statistics Office. 2015. Solomon Islands 2012/13 household income and expenditure survey national analytical report. Solomon Islands National Statistics Office, Honiara, Solomon Islands.

Szaboova, L., K. Brown, and J. A. Fisher. 2020. Access to ecosystem benefits: more than proximity. Society \& Natural Resources 33:244-260. https://doi.org/10.1080/08941920.2018.1556759

Tan, P. Y., and R. Samsudin. 2017. Effects of spatial scale on assessment of spatial equity of urban park provision. Landscape and Urban Planning 158:139-154. https://doi.org/10.1016/j. landurbplan.2016.11.001

UN-Habitat. 2012. Solomon Islands: national urban profile. UNHabitat, Nairobi, Kenya.

Unnikrishnan, H., and H. Nagendra. 2015. Privatizing the commons: impact on ecosystem services in Bangalore's lakes. Urban Ecosystems 18(2):613-632. https://doi.org/10.1007/ $\underline{\mathrm{s} 11252-014-0401-0}$

Wieland, R., S. Ravensbergen, E. J. Gregr, T. Satterfield, and K. M. Chan. 2016. Debunking trickle-down ecosystem services: the fallacy of omnipotent, homogeneous beneficiaries. Ecological Economics 121:175-180. https://doi.org/10.1016/j.ecolecon.2015.11.007 
Woodhouse, E., K. M. Homewood, E. Beauchamp, T. Clements, J. T. McCabe, D. Wilkie, and E. Milner-Gulland. 2015. Guiding principles for evaluating the impacts of conservation interventions on human well-being. Philosophical Transactions of the Royal Society B: Biological Sciences 370(1681):20150103. https://doi.org/10.1098/rstb.2015.0103 


\section{Appendix}

Table A.1. Comparisons of socio-demographic characteristics between urban and rural dwellers.

\begin{tabular}{|c|c|c|c|c|}
\hline \multicolumn{3}{|c|}{ Socio-demographic characteristics } & \multicolumn{2}{|c|}{$\begin{array}{l}\text { Urbanization } \\
\text { level }\end{array}$} \\
\hline Variable & Description & Category & Urban & Rural \\
\hline \multirow[t]{2}{*}{ Gender } & \multirow[t]{2}{*}{ Recorded as male or female. } & Female & 49 & 53 \\
\hline & & Male & 51 & 47 \\
\hline Age & $\begin{array}{l}\text { Recorded in years. Divided into } 9 \\
\text { categories for analyses }(18-24 ; 25- \\
29 ; 30-34 ; 35-39 ; 40-44 ; 45-49 ; 50- \\
54 ; 55-59 ; 60+)\end{array}$ & Mean & 36.4 & 44.1 \\
\hline \multirow[t]{4}{*}{ Education level } & \multirow{4}{*}{$\begin{array}{l}\text { What level of school respondents had } \\
\text { completed: 1) None to elementary; 2) } \\
\text { junior secondary and professional, } \\
\text { e.g., carpentry; 3) senior secondary; } \\
\text { and 4) tertiary. }\end{array}$} & 1 & $26 \%$ & $50 \%$ \\
\hline & & 2 & $17 \%$ & $24 \%$ \\
\hline & & 3 & $32 \%$ & $12 \%$ \\
\hline & & 4 & $25 \%$ & $14 \%$ \\
\hline \multirow[t]{2}{*}{$\begin{array}{l}\text { Time in } \\
\text { community }\end{array}$} & \multirow{2}{*}{$\begin{array}{l}\text { Number of years living in the } \\
\text { community divided by the person's } \\
\text { age. }\end{array}$} & Mean & 14.0 & 34.3 \\
\hline & & SD & 11.9 & 20.0 \\
\hline \multirow[t]{2}{*}{$\begin{array}{l}\text { Material wealth } \\
\text { (Material style of } \\
\text { life) }\end{array}$} & \multirow{2}{*}{$\begin{array}{l}\text { PCA loading for one factor based } \\
\text { grouping scores of presence of more } \\
\text { modern types of amenities (Table } \\
\text { A.2). }\end{array}$} & Mean & 0.73 & -0.73 \\
\hline & & SD & 0.83 & 0.49 \\
\hline
\end{tabular}


Table A.2. Material Style of Life Principle Component Analysis (PCA) factor loading.

\begin{tabular}{lr}
\hline Variable & $\begin{array}{r}\text { Factor } \\
\text { loading }\end{array}$ \\
\hline Water source & 0.48 \\
Toilet facility & 0.75 \\
Electricity access & 0.84 \\
Cooking facility & 0.69 \\
Lighting source & 0.86 \\
Roof materials & 0.60 \\
Refrigerator & 0.67 \\
Radio & 0.18 \\
Television & 0.78 \\
Mobile phone & 0.47 \\
Computer & 0.66 \\
Mean of transportation & 0.33 \\
\hline
\end{tabular}


Table A.3. Description of the ecosystem services used in this study and correspondence with CICES (Haines-Young and Potschin, 2018).

\begin{tabular}{|c|c|c|}
\hline $\begin{array}{l}\text { Ecosystem } \\
\text { service }\end{array}$ & $\begin{array}{l}\text { Corresponding CICES names at } \\
\text { the class level }\end{array}$ & $\begin{array}{l}\text { Description given to interview } \\
\text { participants }\end{array}$ \\
\hline \multicolumn{3}{|c|}{ Provisioning services } \\
\hline Food & $\begin{array}{l}\text { (1) Cultivated terrestrial plants } \\
\text { (including fungi, algae), (2) plants } \\
\text { cultivated by in- situ aquaculture, ( } 3 \text { ) } \\
\text { animals reared, (4) animals reared by } \\
\text { in-situ aquaculture, (5) wild plants } \\
\text { (terrestrial and aquatic, including } \\
\text { fungi, algae), and (6) wild animals } \\
\text { (terrestrial and aquatic) used for } \\
\text { nutritional purposes. }\end{array}$ & $\begin{array}{l}\text { Food from plants and animals } \\
\text { (including fish) that are grown/reared } \\
\text { or harvested in nature. }\end{array}$ \\
\hline Materials & $\begin{array}{l}\text { (1) Fibres and other materials from } \\
\text { cultivated plants, fungi, algae and } \\
\text { bacteria, (2) fibres and other materials } \\
\text { from wild plants for direct use or } \\
\text { processing. }\end{array}$ & $\begin{array}{l}\text { Materials from plants and animals, } \\
\text { e.g. building materials and medicine } \\
\text { that are grown or harvested in nature. }\end{array}$ \\
\hline Firewood & $\begin{array}{l}\text { (1) Cultivated plants (including fungi, } \\
\text { algae), (2) wild plants (terrestrial and } \\
\text { aquatic, including fungi, algae) used } \\
\text { as a source of energy. }\end{array}$ & $\begin{array}{l}\text { Fuel from plants for cooking or } \\
\text { lighting that are grown or harvested in } \\
\text { nature. }\end{array}$ \\
\hline \multicolumn{3}{|c|}{ Regulating services } \\
\hline Clean air & $\begin{array}{l}\text { Filtration/sequestration/storage/accum } \\
\text { ulation by micro-organisms, algae, } \\
\text { plants, and animals }\end{array}$ & $\begin{array}{l}\text { Plants that clean the air, e.g. by } \\
\text { removing dusts and pollutants. }\end{array}$ \\
\hline Clean water & $\begin{array}{l}\text { Filtration/sequestration/storage/accum } \\
\text { ulation by micro-organisms, algae, } \\
\text { plants, and animals }\end{array}$ & $\begin{array}{l}\text { Plants and animals that clean the } \\
\text { water (filtrate wastes). }\end{array}$ \\
\hline $\begin{array}{l}\text { Soil } \\
\text { protection }\end{array}$ & Control of erosion rates & $\begin{array}{l}\text { Plants and animals that prevent soil } \\
\text { erosion (e.g., plant roots that stabilise } \\
\text { the soil) and protect the coast (e.g., by } \\
\text { reducing waves). }\end{array}$ \\
\hline
\end{tabular}

\section{Cultural services}

Recreation (1) Characteristics of living systems that that enable activities promoting health, recuperation or enjoyment through active or immersive interactions, or (2) through passive or observational interactions.
Places for activities or to relax and have an enjoyable time (e.g., activities to come together, swimming, walking). 


\begin{tabular}{lll}
\hline Culture & $\begin{array}{l}\text { (1) Characteristics of living systems } \\
\text { that are resonant in terms of culture or } \\
\text { heritage, (2) elements of living } \\
\text { systems that have symbolic meaning, } \\
\text { or (3) sacred or religious meaning }\end{array}$ & $\begin{array}{l}\text { Culture, heritage and traditional } \\
\text { knowledge associated with nature } \\
\text { including stories, tambu plants and } \\
\text { animals. }\end{array}$ \\
Stewardship & $\begin{array}{l}\text { (1) Characteristics or features of } \\
\text { living systems that have an existence } \\
\text { value, or (2) have an option or } \\
\text { bequest value. }\end{array}$ & $\begin{array}{l}\text { Protect or conserve plants, animals } \\
\text { and nature for their own value or for } \\
\text { future generations. }\end{array}$ \\
\hline
\end{tabular}

HAINES-YOUNG, R. \& POTSCHIN, M. B. 2018. Common International Classification of Ecosystem Services (CICES) V5.1 and Guidance on the Application of the Revised Structure. Available from www.cices.eu. 